\title{
ВОЗМОЖНОСТИ ДИНАМИЧЕСКОЙ ДВУХИНДИКАТОРНОЙ СЦИНТИГРАФИИ ЩИТОВИДНОЙ ЖЕЛЕЗЫ В ДИФФЕРЕНЦИАЛЬНОЙ ДИАГНОСТИКЕ УЗЛОВЫХ ОБРАЗОВАНИЙ
}

\author{
Криволапов Д.С., Ромащенко П.Н., Майстренко Н.А., Бойков И.В., Вшивцев Д.О. \\ ФГБВОУ ВО «Военно-медицинская академия имени С.М. Кирова» МО РФ
}

В последние годы отмечена тенденция к увеличению числа больных фолликулярными неоплазиями и раком щитовидной железы (ЩЖ), которая требует разработки новых методов диагностики, позволяющих дифференцировать доброкачественные и злокачественные узловые образования (УО). Одним из таких методов является динамическая двухиндикаторная сцинтиграфия щЖ с ${ }^{99 \mathrm{~m} T c-п е р т е х н е т а т о м ~}$ и ${ }^{99 m}$ Тс-технетрилом. Однако общеизвестная визуальная методика оценки ее результатов не позволяет достичь высоких показателей информативности и диктует необходимость дальнейшего изучения и модификации сцинтиграфии.

ЦЕЛЬ: модифицировать методику оценки результатов динамической двухиндикаторной сцинтиграфии ЩЖ с ${ }^{99 \mathrm{~m} T c-п е р т е х н е т а т о м ~ и ~}{ }^{99 \mathrm{~m} T c-т е х н е т р и л о м ~ и ~ о ц е н и т ь ~ е е ~ в о з м о ж н о с т и ~ в ~ д и ф ф е р е н ц и а л ь н о и ̆ ~ д и а-~}$ гНОСТИКе УО.

МАТЕРИАЛЫ И МЕТОДЫ: основу работЫ составили результаты обследования и хирургического лечения 56 пациентов с заболеваниями ЩЖ, которые были разделены на ретроспективную $(\mathrm{n}=17)$ и проспективную (n=39) группы. Общепринятое обследование больных дополняли выполнением динамической

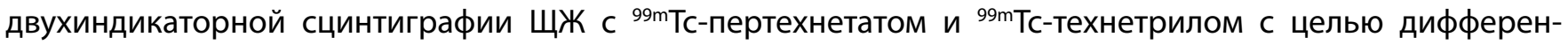
циальной диагностики доброкачественных и злокачественных УО. В ретроспективном исследовании анализ результатов исследования осуществляли по общепринятой визуальной методике, где классическим результатом, указывающим на злокачественность, считали сочетание «холодного» УО в фазу сканирования с ${ }^{99 \mathrm{~m} T c-п е р т е х н е т а т о м ~ с ~ п о с л е д у ю щ и м ~ а к т и в н ы м ~ н а к о п л е н и е м ~ в ~ н е м ~}{ }^{99 \mathrm{~m}}$ Тс-технетрила. В проспективной группе модернизирована визуальная методика посредством создания системы, основанной на выделении 3-х моделей УОЩЖ в зависимости от показателей поглощения ими ${ }^{99 \mathrm{~m}} \mathrm{Tc-пертехнетата}$ и ${ }^{99 \mathrm{~m} T c-т е х н е т р и л а, ~ а ~ т а к ж е ~ р а з р а б о т а н а ~ о р и г и н а л ь н а я ~ м е т о д и к а ~ п о л у к о л и ч е с т в е н н о г о ~ а н а л и з а ~ д а н н ы х ~}$ путем расчета индекса вымывания (ИВ ${ }^{99 \mathrm{~m}}$ Тс-технетрила в раннюю и позднюю фазы сканирования в УО, отнесенных ко 2 и 3 моделям.

РЕЗУЛЬТАТЫ: Анализ результатов применения сцинтиграфии у 17 больных ретроспективного исследования показал, что ее чувствительность в выявлении папиллярного рака ЩЖ составила 90,9\%, специфичность 50\%, точность 76,4\%, положительная прогностическая ценность 76,9\%, отрицательная прогностическая ценность 75\%. Выделение 3-х моделей УО при визуальной оценке результатов исследования у больных проспективного исследования позволило повысить показатели информативности до 70\%, $93,1 \%, 87,2 \%, 77,8 \%$ и 90\% соответственно. Оценка ИВ 99mТс-технетрила в УО осуществлена у 35 больных. Были получены его значения в диапазоне от 5,3\% до 57,3\% и установлено, что УО с индексом вымывания более $40 \%$ соответствовали коллоидным узлам, от $40 \%$ до $20 \%$ - фолликулярным аденомам, менее $20 \%$ - папиллярным карциномам. Показатели информативности методики составили 100\%, 92\%, 94,3\%, $83,3 \%, 100 \%$ соответственно.

ВЫВодЫ: Модифицированная методика оценки результатов динамической двухиндикаторной сцинтиграфии ЩЖ с ${ }^{99 \mathrm{~m} T c-п е р т е х н е т а т о м ~ и ~}{ }^{99 \mathrm{~m} T c-т е х н е т р и л о м ~ п о з в о л и л а ~ п о в ы с и т ь ~ п р а к т и ч е с к и ~ в с е ~ п о к а з а т е-~}$ ли информативности до 100\%, что дает возможность избежать тонкоигольной аспирационной биопсии и выявлять папиллярный рак ЩЖ при наличии подозрительных на злокачественность сонографических характеристик УО, а также проводить дифференциальную диагностику фолликулярных неоплазий. 